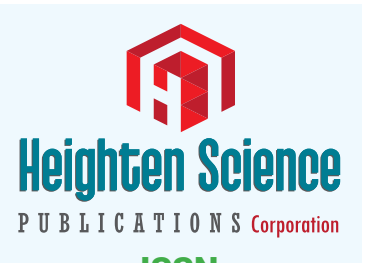

ISSN

2639-9911

\title{
Behavioral transformation through inner conflict resolution: A new Nursing Theory
}

\author{
Thomas A Sharon* \\ DNP, MPH, ARNP-BC, Clinical Nurse Practitioner at Touro University Nevada, Nevada, USA
}

*Address for Correspondence: Dr. Thomas A Sharon, DNP, MPH, ARNP-BC, Clinical Nurse Practitioner at Touro University Nevada, Nevada, USA, Tel: (305) 917-3032; Email:

Thomas.Sharon@tun.touro.edu

Submitted: 12 July 2018

Approved: 26 July 2018

Published: 27 July 2018

Copyright: @2018 Sharon TA. This is an open access article distributed under the Creative Commons Attribution License, which permits unrestricted use, distribution, and reproduction in any medium, provided the original work is properly cited

Check for updates

\section{Abstract}

The discipline of Hassidic Philosophy, which emanates from a particular movement in Orthodox Judaism called Hassidism, begins with the premise that all of creation is a dichotomous world of opposites with both sides in a perpetual conflict with one another. The human construct is therefore a dichotomous spiritual entity manifested in the physical world through a mind-body. One side of this soul is the Godly intellect giving rise to the human identity or self-awareness and the other side is the animal soul whose purpose is to galvanize the body. Having learned that this discipline provides its followers with tools for behavioral transformation through inner conflict resolution, I find that it offers a clearer understanding of the spiritual component of holistic health and nursing theory as well as a tool for behavioral transformation that has practical application in nursing practice. Therefore, the purpose of this paper is to present the basic constructs of Hassidism as it pertains to human behavior, demonstrate its compatibility with existing nursing theory and offer a new methodology for advanced practice nurses (APN's) to assist their clients in achieving behavioral transformation through inner conflict resolution.

\section{Introduction}

\section{Philosophical assumptions}

Hassidism explains that human perception and understanding of reality is dependent on the concept of opposites. For example, we can't distinguish light without darkness, because without it we wouldn't be able to understand what light is. Without evil we wouldn't know how to be good, we can't be kind if we don't know what it means to be cruel, we can't feel love without knowing about hate and so on. Moreover, since the opposite of something is nothing, the only way we can know that anything exists is to understand "nothingness." Hassidic philosophers have elucidated that just as everything in nature has its opposite like positive and negative currents in electricity, which are diametrically opposed to one another, the human spiritual construct is similarly a dichotomy of two opposing positive and negative powers; the animal soul, vitalizing the body with the drive to survive and the Godly soul giving rise to self-awareness and intellect. This concept in human spirituality represents inner conflict; the knowledge, of which, provides an opportunity to develop a tool for healing and maintaining wellness. The Hassidic spiritual advisor identifies and defines the perpetual conflict within the human spirit as the basis for understanding destructive impulses and how to control them.

The best-known opus of Hassidism is the Tanya (the Hebrew word for "teachings"); a book of Kabbalah which Rabbi Schneur Zalman of Liadi Russia compiled over a number of years, publishing the first edition around 1799. He was a Jewish spiritual leader and mystic who had an inexplicable level of knowledge of medicine and science that was well beyond his time. In many Jewish communities and schools, adults and children study the Tanya daily and consider it as an essential and indispensable part of Jewish life. Rabbi Zalman taught that the human spirit consists of two contradictory 
entities that are constantly waging war with each other to gain control of the mindbody. These two enemies are the human intellect versus the animal emotion. In Kabbalistic terms it is the "good inclination versus the evil inclination," or "the Godly soul versus the animal soul." Moreover, the origin of all thought and emotion emanates from the polarized human spirit; split between the higher level human soul (created in God's image) and the lower level animal soul (created to galvanize the body). Hence, every act is an answer to the question, "Should I or should I not?" And, as such, human behavior is simply a manifestation of whether the human or the animal won control of the moment. The Hassidic follower learns that thought, speech and action are the three garments of the soul and people are continuously deciding whether to think a particular thought, say a particular word and/or engage in a particular act.

\section{Application of hassidism to nursing theory}

Since nursing researchers have long recognized that there is a spiritual component of being human that influences health and well-being as both cause and effect; it's not surprising to find a great deal of compatibility between Hasidic Philosophical assumptions and established nursing theories. Sister Callista Roy, R.N., Ph.D. based her assumptions regarding her adaptation theory on human purposefulness within a spiritual framework [1]. Other nurse-theorists have focused on the understanding of the spirituality of humankind as a critical component of nursing care and recognized that Roy's adaption model serves as a gateway to exploring human spirituality as a new paradigm in nursing science. Neil Henery pointed out that science and religion are not mutually exclusive and that science alone is powerless to enhance a sense of personal meaning in the face of loss, suffering and/or death [2]. Similarly, Dr. Pamela Reed viewed human spirituality as a distinct paradigm in nursing. She concluded that investigators can and should study human spirituality utilizing standard models for developing conceptual, empirical, and clinical knowledge [3].

Dr. Donna S. Martsolf suggested that human spirituality, as the third pillar of holistic concepts in nursing, lacks definition. She concluded that the spiritual aspects of nursing involve meaning-seeking purpose, values-standards of conduct; transcendenceexperiencing dimensions beyond the self; connecting-relationship with a greater power that exists beyond one's perception of reality; and becoming-reflecting on one's life experience to determine purpose [4].

\section{Concepts}

I have based my nursing practice over the last 35 years on the nursing process first described by [5], which is a series of progressive nursing actions for the purpose of helping a client to reach a goal of healing and well-being through assessment, diagnosis, intervention and outcomes analysis. Although Orlando initially applied her theory in the mental health environment, it soon became apparent that it was applicable to all types of nursing specialties. In 1977, Virginia Henderson, in attempting to define the nursing profession relied on the nursing process as a foundational tool to help nurses focus their attention on the psychosocial aspect of reaching a goal of health and wellbeing. Thus the nursing process with the nursing diagnosis, care plan and intervention as the principle means of implementation had become well entrenched in basic nursing education and practice when I began my nursing career in 1977 [6]. As the years rolled by, I began to incorporate Dr. Sheryl Cox's concept of "patient-centered care" shortly after she published [7]. It made sense since the primary focus of the nurse has always been the client. Dr. Cox proposed patient-centered care as "concept, construct and process" with the client achieving sustained behavioral changes as the principle determining factor in attaining favorable outcomes.

In this current work, it becomes apparent that Cox's theory of sustained behavioral change can be the chief determinant of improved outcomes in healthcare. This concept provides an excellent basis for developing new methodologies to assist clients to 
achieve the "sustained behavioral change" in advanced nursing practice. Accordingly, I propose the concept of a dichotomous conflicted human soul as the universal construct of the human psyche with inner conflict resolution as the means by which to achieve improved outcomes in the self-management of chronic illness.

\section{The duality of self = human intellect versus animal emotion}

In a manner of speaking, people are half animal and half human. This antagonistic bifurcation between selfless intellect and self-absorbed instinct is our physical and spiritual construct and understanding how it works allows one to gain access to healing and disease prevention. Each half has opposite perspectives and motivations; the animal's self-interest versus the human's interest in the well-being of others. The animal uses cunning to gain instant gratification while the human employs logic with the ability to defer immediate indulgence to achieve the best possible outcome in the longer term.

Therefore, since healing and wellness are reliant upon behavior, subduing the internal animal with a proverbial harness is a matter of embarking on a campaign to win the internal war against a ruthless, powerful and cunning adversary. So the first step on the road to victory in any adversarial situation is to gather intelligence about the enemy's strengths, weaknesses and predictable behavior patterns. Thereby knowing one's own animalistic predilections facilitates reaching any health-related goal.

\section{The internal struggle for dominance determines our state of health}

In relating these Hassidic concepts to healing and wellness in a modern world, we need to understand that the struggle for dominance between the intellect and emotion determines our state of health and influences the course and outcome of any disease. For example, the whole idea of managing chronic illness is overcoming temptation. The prospect of managing a disease establishes a new conflict between continuing the current life-style and altering it. Overcoming such temptation requires effort in making sacrifices to prolong life and improve its quality. In a related endeavor, [8] explored the concept of spiritual care in nursing, from a hermeneutical phenomenological orientation, as a means to teach Jordanian Muslim men with coronary artery disease to take personal responsibility for their respective outcomes. The authors concluded that a person's religious belief system establishes a code of conduct that could either enhance or impede the life-style changes required to improve outcomes in managing chronic illness.

Recognized a number of "psychosocial barriers" to favorable outcomes in diabetes self-management. These authors presented a comprehensive review of the literature and proposed a complex analysis of social and behavioral factors such as interpersonal relationships, spiritual belief system, self-concept, etc [9]. They mentioned reactive depression as a major barrier; suggesting that this human response to the disease exacerbates the condition. Accordingly, when people find out that they have diabetes, the advanced practice nurse can educate them to understand that diabetes establishes a new struggle between satisfying the craving for sweets (emotion) and reaping the future benefits of keeping the blood sugar within normal limits (intellect) thereby exercising impulse control.

\section{The "Anatomy" of thought}

The dichotomous human mind, which manifests through the various components of the brain, is likewise comprised of integrated parts. The intellect's components are reason, which is a combination of knowledge, understanding and wisdom, and the positive attributes of love, humility and selflessness (all characteristics of Godliness). The emotion is the opposite of the intellect. The counter parts to reason are the three drives - thirst, hunger and sex; and the reverse of the three positive attributes are hate, arrogance and self-interest. 


\section{Intellect-the human identity}

The intellect, which is the Godly side of the soul, pertains to one's awareness of being. It's the spiritual self and thus has no physical presence. Nonetheless, the intellect expresses itself in the physical realm through thought, speech and action utilizing the mind-body to interact with and within a physical environment. The universal nursing application of this concept is in the understanding that the driving force of our bodies is a non-physical intelligence intertwined with emotion that is continuously receiving and processing information and making self-improvement decisions while trying to resist the temptation to fulfill those desires that have harmful consequences.

The human intellect, therefore, has a constitution and purpose. It is organized energy clothed in a physical structure. It provides us with the ability to discern right from wrong and adhere to established moral values. The intellect contains all of the positive attributes that is part of the make-up of every person-reason, love, compassion, humility, and selflessness. They are part of our nature and no person can claim to have invented them.

\section{Reason - knowledge, understanding and wWisdom}

The Hassidic philosophy expounded in the Tanya [10] provides hierarchal definitions of knowledge, understanding and wisdom to provide spiritual insight to human reasoning. Knowledge is the retention of new information that enters through the various organs employed in receiving it. Once the brain perceives a visual signal, auditory, tactile, oral and/or olfactory stimulus or all five, the intellect interprets those and uses the brain to store the information as memory to be retrieved when needed. However, to understand this process from a Hassidic perspective, we transcend the mundane physical realm of electrochemical impulses and imprints to explore the spiritual nature of free will and decision-making. Understanding is a higher level of the thought process. It is a moment of great satisfaction when one suddenly looks up and says, "Aha!" This is the point when the intellect has completed an evaluation of its prior choices and is able to institute changes in behavior exercising more control over some of the destructive impulses generated by needs and desires. Wisdom pertains to our intellectual potential and describes the ability to discern the quality of information that the mind would allow itself to absorb in order to utilize the acquired knowledge.

\section{The positive human attributes-love, humility and selflessness}

According to Hassidic philosophical assumptions expounded in the Tanya, this construct shows the attributes of love, humility and selflessness as being positive emotions subordinate to the human intellect. These qualities exist as inborn potential emanating from the side of Godliness. For Orthodox Jews, love is a matter of law. The idea of love on demand, at first glance, seems unfeasible; however, as a code of conduct requiring behaving toward others as one wants to be treated to achieve a harmonious society, mandated love is logical. Also, there is an inherent potential love for others that exists as part of the Godliness emanating from the soul. Firefighters who run into a burning building to save lives are a prime example of the potential for self-sacrificehumanity driven by the hidden love dominating over animalism, in which resides the instinct for survival at any cost.

Humility is also a natural characteristic of the Godly side of the soul managed by the intellect. The potential for humbleness is the inborn ability of the mind, after much meditation and reflection, to reach the unavoidable conclusion of smallness and insignificance within the incomprehensible vastness of the Universe. This distinction serves to guard one against making ruinous mistakes. This unassuming latency of the human psyche is also the ongoing recognition of one's limitations, frailties and dependencies. 
This aspect of our ability is particularly useful in reaching health related goals because our reflective modesty provides strength in adjusting to adverse changes because it allows us to accept ourselves as we are with a positive outlook. Selflessness in thought, speech and action is a state of being that requires effort to achieve. However, it is a latent part of the Godly human character structure. The effort to bring this latency to full function is in overcoming the animal's self-centeredness.

\section{The emotion-the animalistic nature}

The opposite nonphysical component of human existence is the emotion driven animal side of the soul or life force. It starts with the basic instinct for survival and exists solely to satisfy the needs of the body and is always in conflict with the intellect, although it is neither good nor evil in purpose. It exists solely to satisfy all needs, desires and cravings. The needs pertain to basic requirements for survival and procreationair, water, food and sex. Desires are thoughts of wanting all things that bring about pleasure, and cravings are powerful wants for objects of desire for which there is no immediate access.

All thought, speech, and action stemming from the animal emotion are dedicated to self-gratification. Its existence is somewhat paradoxical because, while it is vital for survival, the animal is also the cause of unhealthy destructive life styles, such as tobacco, alcohol and drug use, eating binges and a sedentary lifestyle. On the other hand, the human draws strength and courage from its animal half in the face of adversity. This is the only source of defense when one perceives a threat. Although the intellect knows that it must fight off an attacker, it cannot muster the required anger and aggression because it does not possess those qualities and therefore must draw upon the animal and allow it to dominate during the moment of danger.

The downside is that the revealed cunning of the animal soul operates from falsehood and attempts to govern the mind-body in a purely self-serving manner. Thus, when a person wrestles with his "conscience," there is a battle raging between the two adversaries. When we observe a multitude of different personalities ranging from extreme generosity to total greed, for example, we are seeing the varying degrees to which one side dominates the other. This is normally a continuous struggle with the outcome in a constant state of flux.

\section{The thirst, hunger and sex drives}

Thirst, hunger and sex drives exist for survival of the individual and the species. This is life at the most rudimentary level. Therefore the "animal" is vital to human existence by providing the drives for hydration, nourishment and procreation. But Human beings have universally organized their societies into making certain that eating, drinking and sexual pursuits are pleasurable. This gives the animal more force to maximize the time and energy spent on pleasure seeking. For people who engage in compulsive eating binges and promiscuity, the animal has gone wild and has dragged the intellect along for the ride. This is an important health issue because negative responses to stressful conditions are rooted in satisfying the basic drives beyond actual need, and cause damage.

\section{The negative human attributes (Hate, Arrogance, Self-interest)}

In contrast to many religious doctrines that speak of hate, arrogance and selfinterest as the "dark" or "evil" side of humanity, such characteristics comprise a vital bag of tools for defense and survival. However, all thought, speech and action emanating from these features can easily have harmful effects without the necessary controls. In other words, these "tools" are actually "weapons" that must be handled cautiously and employed only as a last resort. Hate (aggression) is the ability to express extreme dislike for an object, person or idea. It starts as a thought that generates in response 
to a stimulus that triggers the alarm system. The hate-activator can be a foul odor, a loud noise, an insulting word, a lying politician, a used car salesperson, a telemarketer, a menacing gesture or a terrorist. There is also baseless hatred which is the emotion controlling the intellect to the extent that it cannot differentiate between real and imaginary threats.

Arrogance is a natural part of the animal emotion that gives rise to a self-perception of superiority. The raw emotion is to see oneself as more powerful, smarter and more attractive than anyone. It is rooted in need and not grounded in reality. The irony is the person with unchecked arrogance develops an inflated ego, which becomes more fragile. Self-interest, again, is part of what we need to survive. However, like any loaded weapon, it has the potential for harm. The intellect has to find a balance between being generous and avoiding exploitation.

Theory of inner conflict as the determinant of outcomes in disease management

In order to achieve a practical application of the Hassidic concepts in advance practice nursing I propose the theory that the spiritual inner conflict as described above is the determining factor of chronic illness self-management outcomes. [11], runs along the same lines. Dr. Barrett, whose work is an offshoot of Roger's theory of the Unitary Human Being, proposes a non-causal world view in which the awareness, choices, freedom to act intentionally, and involvement in creating change are the dimensions of behavioral transformation. She explains further that the power to affect change lies in being aware of one's choice, feeling empowered to make the choice and choosing. I would further enhance this premise by proposing the spiritual nature of decision making and free will as expounded herein above. When the animal is in control, then negative outcomes occur. When the human has the upper hand then positive outcomes result. Since the human intellect is constantly fighting for control against the animal instinct and there is a spectrum of control with the animal on one end and the human on the other and the nurse needs to assess the client's current thought process to determine where the client resides within this spectrum of control.

The ability of the individual to adapt to unwanted changes and overcome adversity is dependent upon the extent to which the animal or human spiritual entities are in control of the mind-body. Therefore, there is a need for the nurse to be able to assess where the individual resides on this spectrum.

\section{Summary and Conclusions}

The foundation on which to build the tools of transformation for healing and wellness is the knowledge of the bipolar construction of the world-positive versus negative forces that are in perpetual conflict. The notion of opposites is also the construct of language and governs how we respond to various stimuli that will evoke emotions and inspire logical thinking. According to Hassidic thought expounded in the Tanya, God created everything with an opposite so that we could understand how to behave and make the correct choices by free will. While we are half animal with the ability to respond instinctively for survival, we are half human operating from a Godly intellect. Each half is a spiritual entity which must fight the other for control of the mind-body; the animal whose sole drive is instant gratification versus the human intellect whose sole purpose is to contribute to the betterment of humankind. Ergo, every decision is a function of answering the question, "Should I or should I not?" The answer, to which, depends on which side won the argument. The practical application of Hassidic concepts in advance practice nursing is in teaching the client to understand his/her inner conflict as the root of this tumultuous exercise of decision making and free will with bodily needs, desires and wants always being at odds with rational thoughts of avoiding unintended consequences. 


\section{References}

1. Roy SC. An explication of the philosophical assumptions of the Roy Adaptation Model. Nursing Sci. 1988; 1: 26-34. Ref.: https://tinyurl.com/yb3nmhw7

2. Henery N. Constructions of spirituality in contemporary nursing theory. J Adv Nurs. 2003; 42: 550557. Ref.: https://tinyurl.com/y8d8ckly

3. Reed PG. An Emerging Paradigm for the Investigation of Spirituality in Nursing. Res Nurs Health. 1992; 15: 349-357. Ref.: https://tinyurl.com/y7cktg4r

4. Martsolf DS, Mickley JR. The concept of spirituality in nursing theories: differing world-views and extent of focus. J Adv Nurs. 1988; 27: 294-303. Ref.: https://tinyurl.com/y8fob2z5

5. Schmieding NJ. Ida Jean Orlando: A nursing process theory. Sage Publications. 1993; 61.

6. Henderson V. The Concept of Nursing. J Advanced Nursing. 1978; 3: 113-130. Ref.: https://tinyurl.com/ycnd4cul

7. Lutz BJ, Bowers BJ. Response to Patient-Centered Care: Understanding its Interpretation and Implementation in Healthcare. Sch Inq Nurs Pract. 2000; 14: 165-183. Ref.: https://tinyurl.com/y72fzmxj

8. Naboisi M, Carson A. Spirituality, illness and personal responsibility: the experience of Jordanian Muslim men with coronary artery disease. Scand J Caring Sci. 2011; 25: 716-724. Ref.: https://tinyurl.com/y8esneaz

9. Russell E. Glasgow, PhD, Deborah J. Toobert, PhD, Cynthia D et al. Psychosocial Barriers to Diabetes SelfManagement and Quality of Life. Diabetes Spectrum. 2001;14:33-41. Ref.: https://tinyurl.com/ydg7sx4f

10. Wineberg Y, Lessons in Tanya: The Tanya of Rabbi Schneur Zalman of Liadi. Kehot Publication Society, Brooklyn, New York. 1998.

11. Barrett EAM. Power as knowing participation in change. Nursing Science Quarterly. 2010; 23: 47-54. Ref.: https://tinyurl.com/ycanu3ra 